\title{
High School Students' Questions About Science and Religion in School Debates with Scientists
}

\author{
Ana Cristina Torres ${ }^{1 *}$, João Paiva ${ }^{2}$, Ana Mouraz ${ }^{1,3}$ \\ ${ }^{1}$ CIIE - Centre for Research and Intervention in Education, Faculty of Psychology and Education Sciences, University of Porto, \\ PORTUGAL \\ ${ }^{2}$ CIQUP, Science Teaching Unit, Department of Chemistry and Biochemistry, Faculty of Sciences, University of Porto, PORTUGAL \\ ${ }^{3}$ Department of Education and Distance Education, Open University, Lisbon, PORTUGAL
}

Received 20 November 2020 - Accepted 9 April 2021

\begin{abstract}
The paper describes an analysis of the questions posed by high school students regarding relationships between science and religion in a series of debates with scientists in public high schools of the northern part of Portugal. The exploratory interpretation of 171 collected anonymous written questions allowed for the detection of fragilities in the students' ideas about the nature of science and the nature of religion, connected with a trend to reject religion using scientism arguments. The findings reinforce a need of revising the fragmented teaching of nature of science and its connections with religion towards a more contextualized approach of diversified episodes of these social endeavours, anchored in life's 'big questions' that allow students to make cross-disciplinary connections. Our analysis also supports the need for more research on students' questions rather than on students' answers in more common research methodologies conducted to inform the development of a more meaningful curriculum.
\end{abstract}

Keywords: high school students, knowledge, predisposition, science and religion, students' questions

\section{INTRODUCTION}

This paper reports on an analysis of high school students' questions posed in debates to stimulate reflection and dialogue on science and religion describing their views and doubts on themes in the intersection between science and religion. It draws on the assumption that the fragmented teaching of science and religion issues in the present school context in Portugal (Paiva, Moreira, Morais, \& Moreira, 2016) does not favour an understanding of the contemporary views of the nature of science and of the nature of religion, thus favouring an internal conflict concerning the acceptance of explanations from both perspectives (Paiva, Morais, \& Moreira, 2016).

Science education has been shaped by historical movements to improve science learning with consequences on schools' science subjects' curricula. A common ground is that science learning benefits from teaching strategies deeply embedded in nature of science issues (Lederman, 2007) and from more context-based approaches (Bennett, Lubben, \& Hogarth, 2007), giving place to recent movements towards a cross-disciplinary science-technology-engineering-mathematics (STEM) perspective, slowly evolving to a wider STEAM movement, when accounting for the arts. These are built upon a post-positivist view of scientific inquiry that highlights its changing nature, and a constructivist view of scientific knowledge described by Lederman (2007) as being tentative, empirically based, subjective, socially and culturally embedded and involving human inference, imagination and creativity. However, research shows that most curricula and teaching practices are historically shaped by a positivist limited approach, either through the rigid set of school subjects, or through the epistemic approaches that shape them (Goodson, 2005). 


\section{Contribution to the literature}

- Understandings of contemporary views of nature of science are compromised by internal conflicts regarding the acceptance of the epistemological and ethical differences between science and religion.

- Questions raised by high school students about science and religion reveal a strict and unproblematic association of science with proof, rationality and certainty and religion with faith/emotion, opinion, and uncertainty.

- The study highlights the potential of the analysis of students' questions in providing on how to develop a curriculum more meaningful to the development of better understandings of the nature of science, including its connections with religion.

That is why an old debate around what should be the aims of science teaching in schools keeps being recovered. Osborne (2007) made the case that contemporary science curricula and practices should be more concerned with educating citizens equipped with scientific literacy competences instead of maintaining its 'foundationalist' character that still emphasizes educating future scientists. Other question concerns with what curriculum emphasis should be adopted and whether it should focus on the science content or on life situations in which science plays a key role, a debate boosted by international assessments like TIMSS and PISA which have been shaping international trends and framing both social and educational policies (Bybee, McCrae, \& Laurie, 2009).

Intertwined with these questions, social studies of sciences have progressively been putting the focus on the social cultures and practices of scientific knowledge, extensively discussed by Knorr Cetina (1999) under the designation of 'epistemic cultures'. These focus on "how we know what we know" (p. 1) including the patterns and dynamics of sciences' practices in given domains of expertise, that is, in relation to each domain's contexts and settings. Structures, processes and object-centred and person-centred relationships in which science is produced gain importance in understanding its products, and more importantly, the dynamics of knowledge. The 'relational dynamics' of science jump into the spotlight, and scientific knowledge is more and more explained through scientific actors, research apparatuses and the enactment of structures of meaning. Therefore, while scientific practices produce and maintain (explicit) knowledge or facts, the processes are increasingly stressed out over the products, and objectivity - still much a science "brand" - loses some terrain to subjectivity. The symbolic-expressive aspects of human behaviour and how they are poured upon scientific knowledge gain importance (Knorr Cetina, 1999). Consequently, understanding science becomes a matter of gaining 'epistemic insight' which Billingsley and Hardman (2017, p. 57) described as having "a deep understanding of how knowledge works". Science education for epistemic insight strategically bridges subject borders and is intended to help teachers identify and address any gaps and confusions in students' developing thinking about ways to address the "Big Questions". Epistemic insight becomes a dimension of students' intellectual development (Billingsley \& Hardman, 2017), one that allows to understand the diversity of epistemic cultures within science and how other dimensions of the social sphere are deeply embedded, namely religion. However, discussions in which science and religion are brought together are highly controversial. Reiss (2010) has explained the controversial character of such a relationship with the differential in understandings of reality and in the instrumental use of evidence and authority in the two domains. Whereas Starr (2010) has located the often perceived opposites between science and religion in a distinction between proof and faith, in which language is often a strong mediator. Fact is that this often conflicted views interfere with understandings of scientific claims in topics frequently addressed in school, being evolutionism the far more iconic example.

Under this set of concerns, a series of debates was organized in Portuguese high schools in which two invited speakers of the natural and physical sciences research community shared their positions and arguments in the religious 'belief/non-belief' axis. After the initial speakers' introduction of their position's case, the students were asked to pose anonymous written questions expressing their own positions, doubts and tensions towards the science-religion debate. As in previous research (e.g., Yasri \& Mancy, 2014), the experience of these debates showed a huge level of interest amongst students in the deepening of the connections and oppositions between science and religion. These issues clearly have not been sufficiently addressed in school, with implications for the students' understanding of the nature of scientific knowledge, namely concerning its intertwining with personal religious beliefs and experiences.

The collected students' questions were analysed with the following objectives: (1) to describe the most frequent themes and dilemmas emerging from high school students' questions; (2) to ascertain the students' explanations of their predisposition towards science or religion. The discussion of findings is focused on some implications for the Portuguese curricula of school 
subjects that traditionally address the issues of nature of science and nature of religion.

\section{LITERATURE REVIEW}

The literature review explores the potential of students' questions and some research about students' ideas on science and religion. It ends with a brief overview of how science and religion are addressed in Portuguese school' subjects.

\section{The Potential of Students' Questions}

The study was based on the premise that students' questions can be quite clarifying about the students' interests, doubts and tensions regarding the sciencereligion debate. The potential of students' questions has been widely described particularly in science learning formal contexts (Chin \& Osborne, 2008). The act of posing questions increases motivation, stimulates students' curiosity, and more specifically "epistemic curiosity" as designated by Chin and Osborne (2008, p. $3)$, and deepens their capacity to think about issues that puzzle them, thus generating hypotheses and possible explanations, and connecting these with previous knowledge, much like in processes of scientific knowledge production. Nevertheless, it seems that students decrease their ability to pose more spontaneous questions as they get older (Chin \& Osborne, 2008), giving place to questions that are much more schoolrelated (Baram-Tsabari, Sethi, Bry, \& Yarden, 2006). As school subjects strongly influence students' curiosity and motivation towards new knowledge (Baram-Tsabari et al., 2006), students need to be stimulated and given conditions in school to pose questions, for example, with social supports (teachers, educators, researchers and peers), and targeted activities that induce students to supply questions (Chin \& Osborne, 2008, p. 34). Furthermore, and regarding school constraints to questioning, more attention is needed to children and young people's questions in informal contexts as a way to inform educational research about the students' interests in science and thus of potential contexts for curriculum development. Some interesting examples can be found in studies of self-generated children and young people questions posed to scientists in a TV and websites (Baram-Tsabari \& Yarden, 2005; Baram-Tsabari et al., 2006). These studies highlighted how Zoology and Human Biology were popular themes, followed by Technology and Astrophysics. Nature of science was amongst the least-covered topics and no mention was made to any relation between science and religion. Some scarce questions of topics regarding evolution and creationism were posed though.

Another interesting study focused on a group of Biology students aged 16-18 and on the questions they posed to scientists on a visit to a biomedical-clinical research institute, noting how students' took advantage of the visit opportunity, not only to explore substantive knowledge regarding Biology issues and epistemological issues of knowledge construction, but also to deepen their understanding of the ethical issues involved not just in scientific research but in the social and cultural issues involved in its application (France \& Bay, 2010). Students used their questions to explore their understanding of the science practice, to make identity links with the researchers and to explore their possible engagement with a science career.

\section{Students' Ideas on Science and Religion}

While the deepening of students' ideas on science and religion through students' questions hasn't been popular, much attention has already been paid to it using other approaches. In the spotlight has been the teaching of critical topics such as the origins of universe and life (e.g., Billingsley, Brock, Taber, \& Riga, 2016) and evolutionary theories (e.g., Yasri \& Mancy, 2014) for the contradictive explanations offered respectively by contemporary science and religious texts, mostly the Christian.

Though high school students tend to be emotionally engaged with Biology topics (Baram-Tsabari et al., 2006), quite often they experience having multiple and conflicted ideas about science (Kohut, 2018) when internally negotiating them with their religious background, which might have much to do with decontextualized teaching often grounded on positivist approaches. These struggles have been diagnosed in several contexts with more or less diverse religious backgrounds. Still, students' ideas on the apparent conflict between science and religion are often situated more on a range between visions of compatibility and incompatibility rather than on extremist ends. For instance, Yasri and Mancy (2014) detected diverse students' positions on the relationship between science and religion, which influenced different types of engagement with learning about evolution. Though positions on the incompatibility side hampered an unconflicted learning about evolution, the authors argued for the possibility of students to change their more incompatible views, if epistemological support is given. Based on the assumption that this support should be provided in schools through cross-disciplinary issues, and specifically on those that bridge sciences and humanities, Billingsley and colleagues (2016) investigated how English secondary school students made sense of their experiences in Science and Religious Education (RE) lessons. This mostly Christian and Atheist set of students perceived a permeable boundary between science and their learning in science lessons and also a permeable boundary between religion and their learning in RE lessons, yet perceived a firm boundary between science lessons and RE lessons. Their findings also reflect how much should still be reformed in schools in terms of science teaching towards a better 
understanding of the nature of science, since students often associated science with fixed ideas of facts, certainty, proof and experiments to prove an idea right or wrong. On the other hand, religion was perceived as a set of opinions that did not need evidence to support them. In sum, a contrast between the association of science to 'facts' and of religion to 'opinions'. One important insight came later from Tang and Yang (2017) who framed the discussion on student agency. They reported how a group of high school Biology students in Singapore viewed and negotiated the relationship between biological evolution and their beliefs in Christianity. The authors described how students in a very unique multi-cultural context exhibited more agency in resolving the conflict between science and religion than literature tends to ascribe based on previous interpretative accounts that emphasised confrontation, alienation and marginalisation. The implication is that students' agency in negotiating the differing worldviews between science and religion should be seen as a resource for the learning of evolution, rather than a hindrance. Another explanation of how students negotiate these often conflicted views comes from Kohut (2018) and his description of the rhetoric of nature of science that students use to defend their often community situated religious positions. On a study with high school students from a rural community, Kohut (2018) found that both students' who identified themselves with evolutionism and others that were creationists presented positive views of science, and the other way around also. The difference seemed to reside on how the students used a certain set of ideas about science, that could be internally negotiated or emerging from their environment's "voices", to defend their position. As Kohut (2018) described, different students can use the same statements about science to argue against or afore evolutionism. Additionally, one individual can dismiss some scientific explanations in one situation, and strongly defend others in another situation.

Back in Portugal, a survey of perceptions and attitudes on science and religion in a group of 308 high school students aged 16-18, predominantly Catholic, revealed how non-believers expressed stronger support for the view that the Bible cannot be read literally, while Catholics expressed higher support for the acceptance of the evolution of species theory (Paiva, Morais, \& Moreira, 2016). In effect, non-believers revealed stronger criticism than Catholic respondents, and argued for religion's progressive loss of importance along with scientific development. Students viewed scientists as being unlikely to have faith and catechists as being in need of learning more about science to support their faith. Paradoxically, non-believers thought that catechesis did not need scientific culture.

\section{Science and Religion in Portuguese School' Subjects}

Portuguese schools' curricula are mostly subjectbased, and Mother Language, English, Sciences (both Natural and Human) and Maths have traditionally more importance as core subjects. In addition, Sciences and Maths are still much perceived and taught as fixed true statements that one must learn without questioning. Either from the subject-based approach or from the affirmative perspective of curriculum delivery, the fact is that each subject is presented and taught within a specificity that depends mostly on the hierarchical sequential level model that the curriculum follows. Therefore, integrative and thematic approaches or problem based-learning are usually seen as strategies to illustrate or practice a previously taught content rather than occasions to foster meaningful learning. The curriculum content itself is also problematic. Following an international trend of linking the teaching of the nature of science topics with the teaching of evolution and the origins of the universe and life (an useful synopsis can be found in Kohut, 2018), teaching of nature of science aspects before high school is almost limited to introducing and discussing disconnected episodes of the history of science when teaching students about connections between science, technology and society, usually the contradictory theories of the origins of the universe and how the Catholic Church influenced their development. This frequently has the side negative effect of promoting a narrowed view of the nature of science, one that only accounts for the religious influences on the scientific endeavour disregarding other important social aspects of scientific development.

Recently, schools were invited to change their curriculum approaches (Mandate no. 5908/2017 from the Portuguese Ministry of Education), namely by giving more room to pedagogical practices that emphasize the mode 2 of knowledge production (Gibbons, Nowotny, \& Scott, 1994) and by fostering students' voice and participation. Much expectation lays on the contributions of such a movement to enlarge epistemic insight and cross boundaries among subjects and marginalised discourses in order to foster the students' knowledge landscape.

Moral and Religious Education is an optional and faith-specific subject, which may be offered to different religions. However, Catholic religion is the most common as a result of a secular religious culture of the Portuguese population. Schools in some larger cities offer other religions courses due to immigration. The Moral and Religious Catholic Education syllabus (MRCE) combines themes from orthodoxy with a broad approach to a humanistic ethics, such as sexuality and human growth, ecology and the origin of the universe (Paiva, Moreira et al., 2016).

When trying to locate the perspectives about religious knowledge that other subjects address, it is 
possible to say that religion is associated to a belief as much as science is associated with rational thinking. Emerging from the curriculum trend that highlighted the historical construction of science - in the 1980s and following the crisis of science from the 1960s (Santos, 1989) -, the opposition between beliefs and reason presented science as the opposite logos to religious discourse. Examples from historical episodes with Galileo, Copernic or Darwin are usually delivered as turning points of scientific development that cut with the religious fundament of the previous dominant knowledge (Santos, 1989). Even integrating the historical character of scientific knowledge production, contents taught in school tend to present facts and evidences in a causal sequence able to explain phenomena while excluding socio-cultural contexts and beliefs. Of course, this does not simply have to do with the prescribed curricula. It is also a problem of textbooks and other teaching materials, as well as of teachers often stereotyped conceptions about science production, largely shaped by previous training and past learning and practice experiences (Mansour, 2015).

\section{METHODOLOGY}

This section introduces the debates in the project "Words n Time" as the context of our study and describes the procedures for collecting and analyzing the students' questions.

\section{Context and Participants: The Debates in the Project 'Words in Time'}

Between 2014 and 2017, a series of debates was organized in 25 public Portuguese high schools within the project 'Words in Time', in a partnership between the University of Porto, the Catholic University and the Portuguese National Center of Culture.

Each debate had an important adversarial dynamic as a core feature with two invited speakers with different positions in the belief/non-belief axis. Speakers came from the domain of natural and physical sciences and shared some personal features: a) interest in science and, in most cases, agents for science; b) interest in the religious phenomenon, though with different belief/non-belief positions; c) openness to dialogue and ability to communicate with high school students. As different speakers were invited to different debates, the covered issues were broad and included creation and origin of the universe theories; ethics, science and religion; the case of Galileo and the tension between science and religion; neurosciences, emotions and religion; artificial intelligence and the "soul" of robots; emergent science issues and the future of science and technology.

The speakers' opening speeches were made in a conversational mode, and both, generally in a converging way, presented a certain apology of science regarding its intrinsic value of curiosity for knowledge and its positive potential for profiting humankind, even if with some degree of ethical dilemma. Afterwards, the speakers highlighted relations between sciences and other fields of knowledge focusing on religious dilemmas. The 'big questions' of tension between science and religion were always mentioned, especially those concerning origins and evolution of the universe and of the human species. Both speakers, whether explicitly or indirectly, explained some of the reasons for belief/nonbelief. The debates were hosted in a cognitive environment that integrated the relationship between knowledge and culture more than the formal learning of subjects.

After an intervention of about 15 minutes for each invited speaker, there was an open debate of approximately one hour between students and speakers. These 90-minute sessions took on time of specific lessons on the students' schedules and included more or less 100 students per session coming from different classes. Some schools organized several sessions with different students. Several hundreds of high school students participated in the debates, with most attending the general course of Sciences and Technology. Students were accompanied by their Sciences and Philosophy teachers, which expected some articulation with subjects' contents such as the evolution of species theory, the origin of the universe, the formation of chemical elements and philosophy of science and of religion. This expectation is fully aligned with the current curriculum reform aims, which is competences based and stresses the importance of an interdisciplinary approach on curricular subjects needed to inform students' citizenship. It also gives place to a more focus on students' role and participation concerning curriculum activities development (Mouraz \& Cosme, 2021).

The debates development had some adjustments set by reality and has not been so much a rigid strategy, $a b$ initio. Once we realized, with the first sessions, that these were more dynamic with the student's active participation, sessions were progressively more guided to respond to the students' interests. We ended up setting initial short interventions and followed by students' questions. A major part of the session was around those same questions. At an early stage, questions were exclusively posed orally. However, we noticed that in large assemblies, most students were timid. We began asking them to pose written questions which were deeper, and facilitated a better organization of the debate, when selected and grouped by themes. This last option proved to be more efficient since students often showed a lot of inhibition to speak of such controversial and personal issues before an assembly of peers and teachers. Some teachers informed us that many questions were further discussed in subsequent lessons, especially during Philosophy classes. Within the Philosophy curriculum of Portuguese secondary 
schools, the science-religion issue is addressed in 11th grade (16K), according to the Essential Learning1. Science and religion are addressed in two different modules, one focusing on the status of scientific knowledge (Philosophy of science) and the other on the religious dimension - analysis and understanding of religious experience (Philosophy of religion). In Portugal, students rarely have to take a national Philosophy exam - unlike the Sciences subjects' exams that are decisive for accessing Higher Education -, allowing for Philosophy teachers to be more willing to ascribe lesson time to open debates.

\section{Collection and Analysis of the Students' Questions}

Data collection had a naturalistic inquiry approach (Patton, 2015) emerging from the described debates drawing mostly on an interpretative qualitative methodology. As previously mentioned, written questions were collected from participant students in all of the debates, after the initial intervention of the invited speakers and before the oral debate. Hence, many of the questions were related with the opening speeches, but not always since, for instance, questions of morality were frequently posed that were often avoided in the opening speeches. Thereafter, research material comprises 171 written questions posed by high school students (aged 16-18) in a total of 155 gathered anonymously cards, with each card corresponding to one individual. In some cases, individuals took advantage of the opportunity to write more than one question, frequently addressed to both speakers. Since the collection of anonymous written questions was intended at contradicting the students' inhibition and sense of exposure, no additional personal information was asked on the cards.

The questions were subjected to a content analysis (Bardin, 2006/1977) of an exploratory nature using NVivo ${ }^{\circledR}$ software. The authors did a first screening of the questions to decide whether the unit of analysis would be the subject or the question, thus being established to split some individuals' questions whenever they referred to different issues. A second analysis was then made by the authors to categorize each question under the following topics/research questions:

1) main themes: which are the main themes and dilemmas that high school students highlight in the intersections between science and religion?

2) predisposition to science and religion: do student questions reflect a predisposition to agree either with science or with religion? Or do they try to conciliate explanations and practices of both? Or a sense of the contradiction of accepting both?

While for the second topic, the authors predetermined categories of predisposition towards science and religion, in the first, most of the categories emerged from the students' words. Categorization of the main themes on the questions was much more straightforward, though. On the contrary, for the second topic, there were some questions that failed to fit any category due to lack of information, thus being classified as 'generic'. The result was a simple two-layered node structure, in which the first-order nodes corresponded to the two aforementioned questions (knowledge and predisposition) and the second-order nodes were the emerging themes and the predetermined predispositions towards science and religion.

Finally, though a simple quantitative count of references/questions in each category was made, we did not attempt for a more thorough quantitative analysis due to the limited amount of research items and lack of supporting information to perform statistical comparisons (e.g., gender, religious background). Hence, the analysis is predominantly interpretative.

\section{FINDINGS}

The findings open with a presentation of the main categorized themes in the students' written questions moving, afterwards, to a summary of the predisposition to science or to religion detected on the analysed questions.

\section{Main Themes in the Students' Questions}

The main themes of the students' questions were grouped into the categories presented in Figure 1.

The majority of the students' written questions in all of the debates had to do with issues that fit into the Catholic religion's dogma and institutions.

Questions about nature and sociology of religion were the most frequent (38), even if in some cases they intertwined with the nature and sociology of science (20). Students often referred to known episodes of the history of Catholic influence in scientific developments, specifically those which are presently addressed in lower secondary curriculum sciences subjects, being the Galileo's conflict with the Catholic Church due to the Heliocentric Theory the most common. But a certain criticism of the Catholic Church's influence in Society could also be noted with questions about its history and inner dynamics (for instance, acceptance of divorced people, women as priests, etc.). These findings align with previous findings of the division between believer and non-believer Portuguese students' attitudes towards religion and science (Paiva, Morais, \& Moreira, 2019). Also, even knowing that they were facing members of the scientific community and not of the religious one, students tended to take the opportunity to resolve some of their struggles with ethical dilemmas that, as reported by Keijo Eriksson (2000), have much to do with issues of the individuals, their relationships and society in connection with the concepts of God and religion.

Some questions also focused on the inner dynamics of the Catholic Church and its dogma, once again 


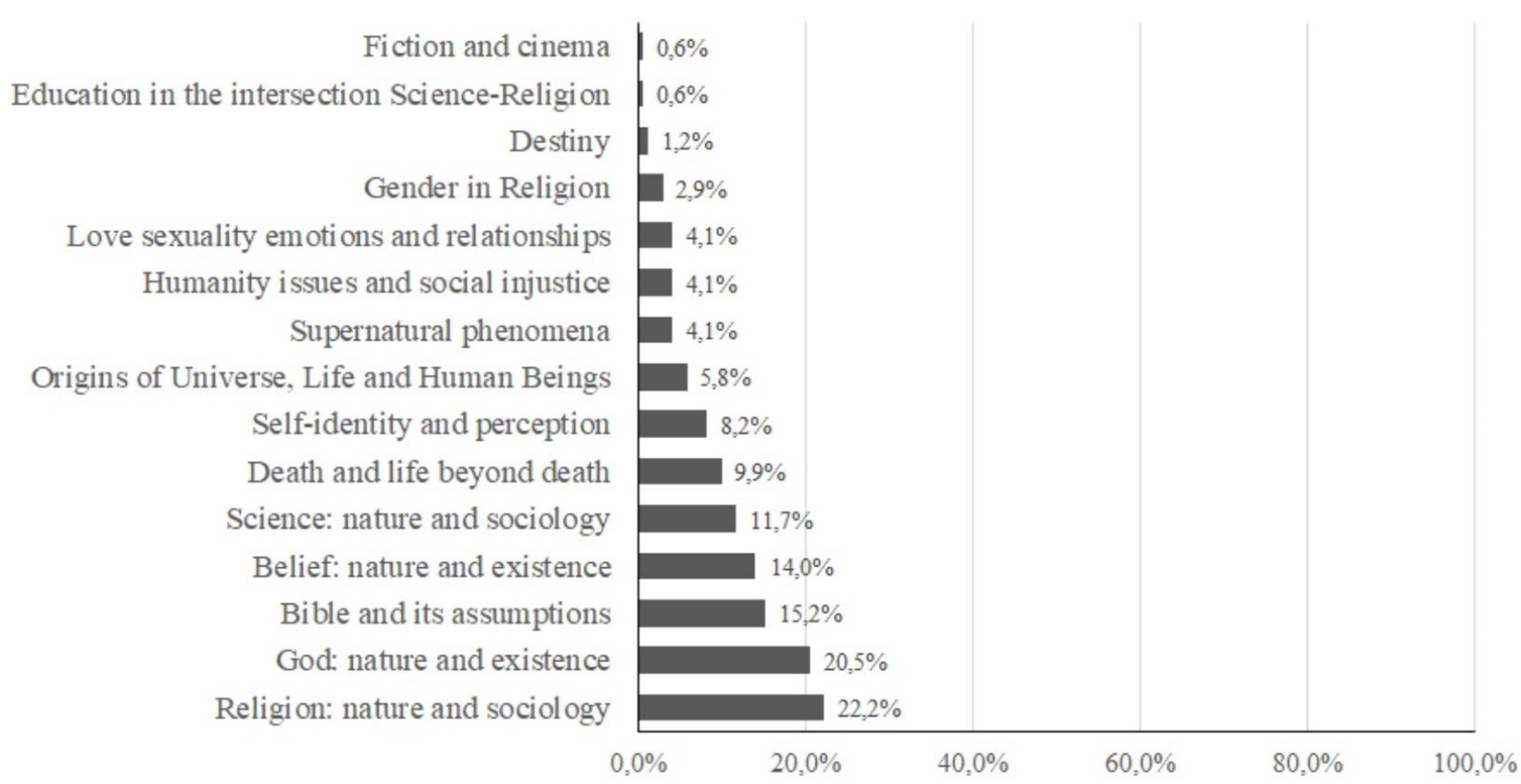

Figure 1. Percentage of questions categorized in each main theme $(\mathrm{N}=171)$

invoking its history, like when asking about the changes in the Bible throughout History and about the believe in a superior being with a man shape. Just as Paiva and colleagues (2019) concluded, students perceive a certain loss of the importance of religion due to modern scientific development when reflecting on "do you believe that scientific development is diminishing religious belief in younger population? (D11.1)".

While the belief in a higher being is a pillar of the Catholic dogma, another frequent theme had to do with the nature and existence of God (35), with questions focusing mainly on the features and assumptions concerning the Christian God, including different individual perceptions of its nature, as well as the existence of scientific evidence to support or reject its existence. This is traditionally an important issue for students in Religious Education (Eriksson, 2000), mostly linked with personal identity, relationship development and societal issues. But while taking advantage of discussing religion issues in a science-based debate, students strived to link a personal concept of God with their personal associations of science with evidence, proof and experiment. Much like in Billingsley and colleagues (2016) study with English students, some of the students asked for "scientific evidence to predict the existence of God? (H13.1)" and requested the speakers' support in helping them figuring out "How do I know God exists? (A8.1)". While asking the believer speaker to elaborate on his "main doubts [that you have regarding] the existence of God? (C11.2)", some students also suggested a certain scepticism regarding the possibility of scientists being believers, just as in previous findings (Paiva et al., 2019).

Another theme that raised a lot of curiosity amongst students was the Bible and its assumptions (26 questions), with questions focused on the figure and episodes of the life of Jesus Christ, the 'creation' of human beings, Heaven and Hell, Adam and Eve. But also questions regarding the metaphorical/literal devise in interpreting the Bible and how it historically evolved over time like "Do you consider that all the Bible is a metaphor or that some of its texts are literal? (A16.1)".

The theme Belief, its nature and existence (24 questions) included the request of arguments to support or reject any type of religious belief, including faith in different religions. It included asking for the speakers arguments on how to reconcile a religious belief in a higher being with science and scientific explanations, for instance, and on their reflections about the differences between a belief and faith.

Questions categorized in the aforementioned, frequently felt also under the theme of Self-identity and perception (14 questions). These showed a need to better understand the role of belief, faith, soul and spirituality in a personal construction as next illustrated: "Is it possible to be an atheist and have spirituality simultaneously? What is the difference between spirituality and religion? (F5.1)".

The nature and sociology of science (20 questions) was also highlighted in questions regarding the relationship between science and society, especially concerning its ethical dilemmas like "With advanced science, if there is the possibility to cure a disease, why are there people who prefer to profit from the treatment of diseases? (A1.2)". But also of internal relationships between scientists. There is little acknowledgement from students about the possibility of scientism as a radical position, when asking, for instance: "Doesn't science as a guide of all 'things' become a religion itself? (A13.1)". And a framing of the issue on the "big questions' of science and religion is also noted when a 


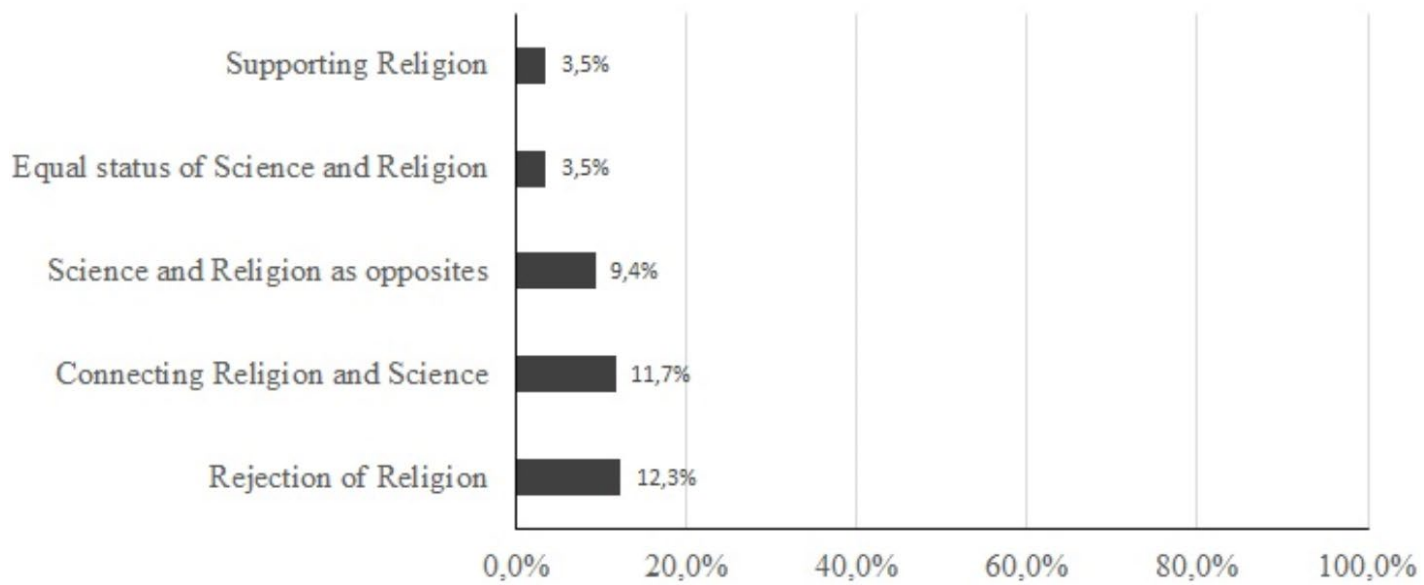

Figure 2. Percentage of questions categorized in each predisposition towards science or religion $(\mathrm{N}=171)$

student asks "Do you think science answers questions of 'how' and 'when'? And religion can answer the question of 'why'? (G15.1)". Some episodes of the history of science, specifically in how the Catholic Church has influenced scientific development, and more general questions asking for more support on how to reconcile religious beliefs with science also fit in here.

In a more conceptual register, there was also some curiosity from students about the speakers' opinion and knowledge about Death and possibility of life beyond (17 questions), mainly related with the meanings and speculation regarding life beyond death, including notions of Heaven and Hell. These accounted for requests of explanations both from religion and science, but the main requests simply asked for the speakers' opinions and explanations. Another emerging theme was confronting the scientific theories of Origins of the Universe, Life and Human Beings (10 questions) with the creationist theories of the Catholic dogma. There were also questions focusing on the imaginary created by Supernatural phenomena (7 questions), such as spirits, witches, phantoms, paranormal, sightings and other phenomena believed to be unexplained by science and more accepted in certain religions. Humanity issues and social injustices (7 questions) also raised some interest, mainly the relations between the religious dogma, values and beliefs (God and Love) and Humanity's social injustices, catastrophes, and conflicts like war, poverty, hunger. Equally frequent were questions regarding Love, sexuality, emotions and loving relationships.

\section{Predisposition to Science or Religion}

Though the majority of the questions were too simple or closed (generic), some were sufficiently open or reflective to be able to be categorized in terms of the predisposition towards science or religion. Figure 2 presents the percentage of categorized questions for the type of predisposition to science or religion.

There was actually almost the same number of questions with a view of a predisposition to reject religion (21 questions) as the number of questions with a predisposition to find connections between religion and science (20 questions).

In the first category, the questions explicitly expressed a criticism of certain assumptions and practices of religion, lowering its importance. Once again, episodes of history were summoned, such as, for example, the ones related with the Inquisition. This reflects a lack of understanding of contemporary postpositivist nature of science. The links between religion and several wide known world conflicts also pose a strong argument to reject religion when asking the speakers, for example, about "don't you think that if there were no religious beliefs there wouldn't be not so many wars/conflicts? (G19.1)". Religion is sometimes also rejected for the difficulty to accept a faith in God when the focus is put on the scientific tasks of collecting proof and evidence, as shown in "according to several (...) a benchmark has been reached in science in which finally they gathered evidence to prove that God is a human invention; I would like to know what is your opinion about this? (D18.1)". These findings align with the ones of Billingsley and colleagues (2016) in which students contrasted the 'facts' and certainty of science with the 'opinions' and uncertainty of religion. Other times, religion is rejected for the overvalue of God on the religious dogma, as in "How is it that religion cannot find any excuses besides 'It was God'? (D6.1)" and for the undervalued options of more personal practices of belief, when asking "Is religion needed nowadays? Isn't belief enough? (F3.1)".

Some questions that showed a predisposition to conciliate scientific explanations with religious beliefs and dogma were just variations of the simple question "How can religion and science relate to each other? (A12.1)". After listening to the speakers' arguments for their positions, the students needed a broader elaboration on the possibilities of links between science and religion, in an attempt to try to develop a 'negotiated view' (Billingsley, Taber, Riga, \& Newdick, 2013). Questions regarding critical topics in science teaching that relate to religious practices also fitted on this category. Questions that summoned knowledge about origin of the Universe 
and evolutionary theories were also present, seeking explanations related with religious beliefs.

There were also some questions in which Religion and science were viewed as opposites (16 questions), since a view of scientific explanations and religious assumptions, practices and dogmas as opposites was expressed, once again with arguments from already mentioned episodes of the history of science, but also with the perception of a contradiction between the practice of science and the possession of a religious belief. For instance, when the believer speaker is asked "as a scientist, saying that science is constantly changing, and that religious beliefs remain constant, don't you consider that it is somehow a paradox to believe in both? (B10.1)" or "if you had to choose between religion and science, what would you choose? Why? (H6.1)".

Questions in which Religion and science were viewed as having an equal status were rarer (6 questions). This was the case of questions that asked for the perspectives on both science and religion regarding specific topics like the origin of universe, the origin of human beings or even the possibility of collecting evidence to support or reject the existence of God. Also rare was an explicit predisposition towards supporting religion (6 questions) and it mainly appeared when support for the importance of having some kind of religious belief was suggested.

But most of the questions were indeed categorized in a generic group due to the fact they did not present any idea that allowed to ascertain a certain predisposition. In most cases, they were just questions to clear a doubt or an opinion of one of the speakers. For instance, "How do I know that God exists? (A8.1)" or "Can you be a believer and a non-believer at the same time? (C9.1)".

\section{DISCUSSION}

The exploratory interpretation of this data raised from the presentations of the scientists' positions towards the religious belief/non-belief axis allowed us to acknowledge unresolved students' questions mainly of nature of both religion and science linked to a trend to reject religion with arguments from scientism. The questions raised by these high school students were situated mostly on the ethical dilemmas within science and religion. These related with the students' concerns often linked to 'hot' topics such as the evolutionism versus literal views of the Bible (Paiva et al., 2019), reflecting the predominant Catholic influence in Portugal and complete disconnection between school subjects that usually address these issues, just as in the English case (Billingsley et al., 2016) (a note to acknowledge also that these students have little knowledge of and reflection about other religions, which can favour the perpetuation of myths and prejudices and, thus, intolerance and cultural diversity ignorance). However, unlike in other contexts, the predominantly Catholic influence does not seem to compromise an acceptance of evolutionism and other theories accepted to explain the observable world, thus posing no risk to the learning of its ideas or underpinning principles. On the contrary, the persistent problem of exacerbation of the evolution/creation and other science/religion conflicts in science classrooms highlighted by Reiss (2010) has seemed, in this case, to reinforce the dismissal of religious ideas leaving individuals in tension to negotiate their own personal beliefs, of a religious or simply spiritual nature. Yet, the students' questions reflect attempts to find scientific explanations to their more individual and personal beliefs often of a spiritual or moral nature. Students seemed to perceive a fixed boundary between the dynamics of science and religion, but pursue bridges between ideas and explanations from both fields. In fact, and just like in previous studies (e.g., Starr, 2010), the questions of students uncover views of a strict association of science with facts, proof, rationality and certainty and religion with faith/emotion, opinion, and uncertainty.

Some limitations of these findings must be acknowledged. Though this study reinforces previous findings for Portuguese high school students' attitudes and perceptions regarding science and religion (e.g., Paiva et al., 2019), the opportunistic nature of this analysis prevents a generalization to wider populations of high school students, even if only Portuguese. The students' selection was not random. Rather it was predetermined by the particularly enthusiastic teachers who registered to participate in the project due to privileged connections with the University, through previous participation in congresses, workshops, training and post-graduation courses.

In this respect, it is important to consider that most of the participant students in these debates were students attending Sciences and Technology courses in high school, thus being more naturally informed and reflective specifically about issues of nature of science and its connections with the social sphere. It is also safe to say that, as the case in England (Billingsley et al., 2016), these students perceived Sciences as a subject with a higher status comparing with Religious Education (optional) or Philosophy (mandatory).

Another issue to consider is that the students' questions were by no means neutral. Rather, they were surely triggered by the speakers' often provocative opening arguments. Still, knowing the richness and diversity of those arguments, it is important to note how these students engaged with the arguments and what mostly caught their attention, even with the equally provocative questions to the speakers that were added to the discussion.

\section{CONCLUSIONS AND IMPLICATIONS FOR CURRICULUM AND SCHOOLS}

The themes and predispositions in the students' questions analysed in this study highlight a persistent 
strict and unproblematic association of science with proof, rationality and certainty and religion with faith/emotion, opinion, and uncertainty. Besides the individual internal tensions this divide may arise, other consequence is that students assign different values to school subjects: science as the valid subject to explain natural and observable phenomena and religious education (but also philosophy) to debate opinions and beliefs. Unlike in the English context, where students are expected in Religious Education lessons to analyse scholars' arguments defending that science and religion are not necessarily incompatible (Billingsley et al., 2016), in Portugal there is an imbalance between the attention given by the religious education curricula - mostly focused on a Catholic faith - to the possibilities of interdisciplinary dialogue with the science curricula and the almost non-existent mention of religion in the science curricula (Paiva, Moreira et al., 2016). In the case of sciences subjects, the relationships between science and religion are addressed mainly recurring to episodes of the history of science such as the contradiction between Copernic's and Galileo's model of the solar system (case of lower secondary education, Year 7). With the pretext of using this episode of history of science to teach students about connections between science, technology and society, it ends up disregarding religion by underlying the ethical-moral positions with prejudice for the development of axiological critical reflection skills (Paiva, Moreira et al., 2016). Equally problematic is the downgrading of the teaching of evolutionary theories, fragmented in small pieces, disconnected concepts and decontextualized facts scattered over different themes of compulsory Natural Sciences subjects in lower secondary education and optional Biology courses in upper secondary education (Abreu, 2011). In sum, by disregarding other important contextual social and historical factors that influence both the development of religion and science, students' risk to fall in conflict negotiating their personal beliefs within their perceived rigid dynamic of science. That is why we concur with Starr (2010) in the idea that science curriculum might not have enough opportunities for students explore unexplained issues, since science classrooms are still much shaped by a positivist approach.

Like Berry Billingsley and colleagues (2016), we believe that these tensions not only interfere with the students' perceived relations between science and religion, but are indicative of how present school teaching seems to undermine the development of an insight of how science relates to the humanities in general. As such, we conclude highlighting the need to revise the fragmented teaching of nature of science and religion issues which are presently scattered over different subjects in the Portuguese curriculum (Sciences, History, Moral and Religious Education, Philosophy) towards more contextualized episodes of these social endeavours anchored in life's 'big questions', allowing for students to actively engage with ethical dilemmas within cross-disciplinary connections.

Curricula contents and teaching practices need to recover the links between processes and products in both science and religion and frame them within the question of 'how do we know what we know?'. It is not enough to report disconnected episodes of the intertwined history of science and religion as is presently the case in Portugal. It is also important to explicitly tackle the cognitive and social processes of deliberation and decision in the dynamics of the scientific and religious community, including the ethical dilemmas involved in such processes.

The challenge is to bring subjects from sciences and humanities together, in learning environments that promote cultural tolerance and individual autonomy (Reiss, 2010), and increasingly value the nature of opinion-making in the science enterprise, permeable to personal and social values and ethical dilemmas.

There is much potential for these connections in the Portuguese curricula, but both teachers and students acknowledge they are not adequately addressed due to lack of opportunity in schools, especially because these students must take national high-stakes exams at the end of the school year. As briefly referred, curriculum reform in Portugal (as worthwhile) is changing in order to give room to students' participation in more active ways in curricular decision. Therefore, the potential of students' questions in developing a more meaningful curriculum is of the utmost importance. The approach of using students' questions rather than their answers is the main notion of this paper as it allows to strengthen the connection between school subjects and students' life experience in a contextualization movement that it is argued inside the curriculum renewing.

Subscribing Kohut's (2018) suggestion of researchers to come up with research tools more able in capturing multiple dimensions and contradictions on students' ideas, our analysis also points to the potential of using students' questions regarding the nature of science and its intertwines with religion, rather than on students' answers. The potential of students' questions in developing a more meaningful curriculum is also to be further explored.

\section{NOTE}

The recent curriculum reform in the Portuguese Basic and Secondary Education Curriculum began to be established in the Students' profile when leaving compulsory schooling (Martins et al., 2017), through the definition of areas of competence to be developed and, afterwards, in the definition of Essential Learning (https://www.dge.mec.pt/aprendizagens-essenciais-0) to be developed in each curricular subject according to those areas of competence and articulated with each other in the horizontal and vertical planes. 
Author contributions: All authors have sufficiently contributed to the study, and agreed with the results and conclusions.

Funding: This work is financed by Fundação para a Ciência e a Tecnologia (FCT) within the project UIDB/00081/2020. Ana Cristina Torres is funded by Fundação para a Ciência e a Tecnologia (FCT) (SFRH/BPD/108950/2015) and by the Centre for Research and Intervention in Education from the Faculty of Psychology and Education Sciences from the University of Porto (UID/CED/00167/2019 and UIDB/00167/2020).

Declaration of interest: No conflict of interest is declared by authors.

\section{REFERENCES}

Abreu, H. (2011). Evolução: O seu ensino em Portugal [Evolution: Its teaching in Portugal]. Açoreana, 7, 369-375.

Baram-Tsabari, A., \& Yarden, A. (2005). Characterizing children's spontaneous interests in science and technology. International Journal of Science Education, 27(7), 803-826. https:/ / doi.org/10.1080/095006905 00038389

Baram-Tsabari, A., Sethi, R. J., Bry, L., \& Yarden, A. (2006). Using questions sent to an Ask-A-Scientist site to identify children's interests in science. Science Education, 90(6), 1050-1072. https://doi.org/ $10.1002 /$ sce.20163

Bardin, L. (2006/1977). Análise de conteúdo [Content analysis]. Edições 70.

Bennett, J., Lubben, F., \& Hogarth, S. (2007). Bringing science to life: A synthesis of the research evidence on the effects of context-based and STS approaches to science teaching. Science Education, 91(3), 347-370. https://doi.org/10.1002/sce.20186

Billingsley, B., \& Hardman, M. (2017). Epistemic insight: Teaching and learning about the nature of science in real-world and multidisciplinary arenas. School Science Review, 365, 57-58.

Billingsley, B., Brock, R., Taber, K., \& Riga, F. (2016). How students view the boundaries between their science and religious education concerning the origins of life and the universe. Science Education, 100(3), 459-482. https:/ / doi.org/10.1002/ sce.21213

Billingsley, B., Taber, K., Riga, F., \& Newdick, H. (2013). Secondary school students' epistemic insight into the relationships between science and religion: A preliminary enquiry. Research in Science Education, 43, 1715-1732. https://doi.org/10.1007/s11165012-9317-y

Bybee, R., McCrae, B., \& Laurie, R. (2009). PISA 2006: An assessment of scientific literacy. Journal of Research in Science Teaching, 46(8), 865-883. https://doi.org/10.1002/tea.20333

Chin, C., \& Osborne, J. (2008). Students' questions: A potential resource for teaching and learning science. Studies in Science Education, 44(1), 1-39. https:/ / doi.org/10.1080/03057260701828101
Eriksson, K. (2000). In search of the meaning of life: A study of the ideas of senior compulsory school pupils on life and its meaning in an experiential learning context. British Journal of Religious Education, 22(2), 115-127. https:/ / doi.org/10.1080/ 0141620000220206

France, B., \& Bay, J. L. (2010). Questions students ask: Bridging the gap between scientists and students in a research institute classroom. International Journal of Science Education, 32(2), 173-194. https://doi.org/10.1080/09500690903205189

Gibbons, M., Nowotny, H., \& Scott, S. (1994). The new production of knowledge: The dynamics of science and contemporary societies. Sage Publications.

Goodson, I. F. (2005). Learning curriculum, and life politics. Routledge. https:/ / doi.org/10.4324/9780203698785

Knorr Cetina, K. (1999). Epistemic cultures: How the sciences make knowledge. Harvard University Press.

Kohut, M. (2018). Changing minds or rhetoric? How students use their many natures of science to talk about evolution. Cultural Studies of Science Education, 14, 839-862. https://doi.org/10.1007/ s11422-018-9865-1

Lederman, N. G. (2007). Nature of science: Past, present, and future. In S. K. Abell \& N. G. Lederman (Eds.), Handbook of Research on Science Education (Vol. 1, pp. 831-880). Lawrence Erlbaum. https://doi.org/ 10.4324/9780203824696-35

Mansour, N. (2015). Science teachers' views and stereotypes of religion, scientists and scientific research: A call for scientist-science teacher partnerships to promote inquiry-based learning. International Journal of Science Education, 37(11), 1767-1794.

https:/ / doi.org/10.1080/09500693.2015.1049575

Osborne, J. (2007). Science education for the twenty first century. Eurasia Journal of Mathematics, Science $\mathcal{E}$ Technology Education, 3(3), 173-184. https:/ / doi.org /10.12973/ejmste/75396

Paiva J., Morais C., \& Moreira L. (2019). If neither from evolution nor from the bible, where does tension between science and religion come from? Insights from a survey with high school students in a Roman Catholic society. In B. Billingsley, K. Chappell, \& M. Reiss (Eds.), Science and religion in education: Contemporary trends and issues in science education (Vol. 48). Springer, Cham. https:/ / doi.org/10.1007/978-3-030-17234-3_21

Paiva, J., Morais, C., \& Moreira, L. (2016). Attitudes towards science and religion: Insights from a questionnaire validation with secondary education students. In Pixel (Ed.), International conference new perspectives in science education: Conference proceedings (pp. 430-434). libreriauniversitaria.it. 
Paiva, J., Moreira, J., Morais, C., \& Moreira, L. (2016). Windows for science-religion dialogue in Portuguese school education. https://crc.up.pt/2018/05/10/ windows-for-science-religion-dialogue-inportuguese-school-education/

Patton, M. Q. (2015). Qualitative Research and Evaluation Methods - Integrating Theory and Practice (4th Ed.). SAGE.

Reiss, M. J. (2010). Science and religion: Implications for science educators. Cultural Studies of Science Education, 5(1), 91-101. https://doi.org/10.1007/ s11422-009-9211-8

Santos, B. S. (1989). Um discurso sobre as ciências [A discourse about sciences]. Afrontamento.
Starr, L. J. (2010). Does anyone really know anything? An exploration of constructivist meaning and identity in the tension between scientific and religious knowledge. Cultural Studies of Science Education, 5(1), 191-200. https:/ / doi.org/10.1007/ s11422-0099227-0

Tang, K.-S., \& Yang, X. (2017). Student agency in negotiating the relationship between science and religion. Research in Science Education, 49(3), 13011317. https:/ / doi.org/10.1007/s11165-017-9655-x

Yasri, P., \& Mancy, R. (2014). Understanding student approaches to learning evolution in the context of their perceptions of the relationship between science and religion. International Journal of Science Education, 36(1), 24-45. https://doi.org/10.1080/ 09500693.2012 .715315

\section{http://www.ejmste.com}

